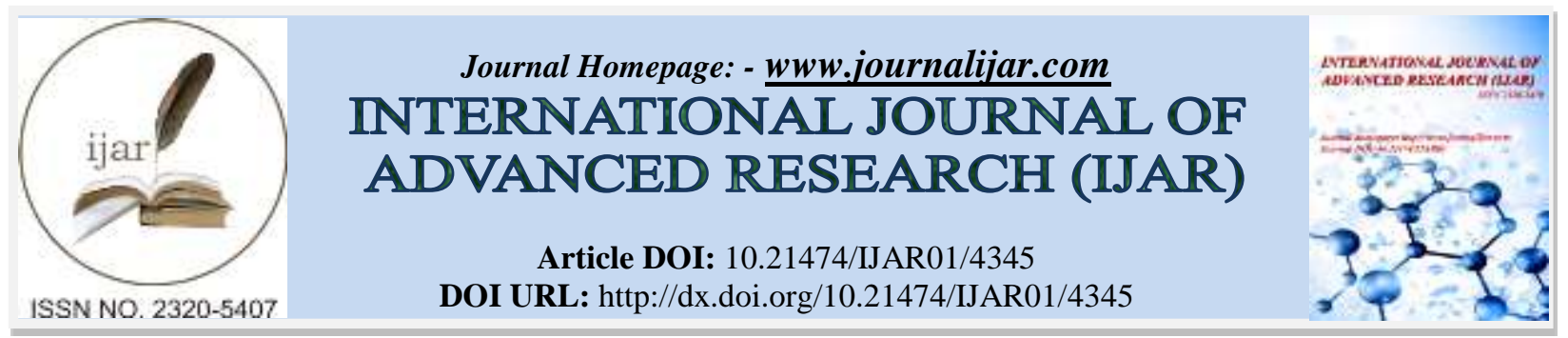

RESEARCH ARTICLE

\title{
STUDY OF PHYSICO-CHEMICAL PROPERTIES AND THEIR CORRELATION STUDY OF DRINKING WATER FROM BORE WELLS OF DIGRAS TALUKA REGION, DIST.- YAVATMAL (M.S.) INDIA.
}

R.R.Wankhade.

Department of Chemistry, B.B.Arts, N.B.Commerce and B.P.Science College, Digras.

\section{Manuscript Info}

Manuscript History

Received: 26 March 2017

Final Accepted: 27 April 2017

Published: May 2017

Key words:-

Correlation co-efficient, ground water, total alkalinity, total hardness, TDS etc.

\section{Abstract}

Now a days use of bore water for drinking purpose is increasing. Physico-chemical characteristics of water samples from 11 bore wells in the region of Digras Taluka were studied. The value of correlation co-efficient (r) of these Physico- Chemical parameters was studied. The values of ' $r$ ' $(>+0.90)$ show significant positive correlation between electrical conductivity (EC), total hardness (TH), total dissolved solids (TDS), chlorine and magnesium.

\section{Introduction:-}

About $97 \%$ of fresh water requirement is fulfilled from Groundwater. Now a days to fulfill the requirement of water for drinking and house hold purposes Bore wells are used. The depth of these bore wells is generally more than $100 \mathrm{fts}$. This ground water contains a high degree of minerals, which depends upon the quality of soil and rocks. Ground water quality is varied due to ecological factors, ground water level, industrialization and agriculture. The main reason of water pollution is industrial and domestic waste, which not only affect water bodies of the area but also exert an impact on physico-chemistry of groundwater. As reported, a correlation may exist among water quality parameters of various samples of same area. A correlation will be helpful for predicting the quality parameters by analyzing few numbers of parameters. Digras taluka as such is not in industrial zone; still study of water quality parameters is necessary due to day to day decreasing groundwater level. Consumption of polluted water can result in serious health problems. In the region of Digras, water requirement is fulfilled by Bore wells. The present study deals with the physico-chemical characterization of water from bore wells of Digras region with correlation between different parameters. The Bore wells used by peoples for water for drinking purpose and house hold activities were selected for the study. Such 11 sources were selected in the present study.

\section{Experimental:-}

The ground water samples from bore wells of Digras taluka region were collected in properly washed polypropylene bottles with necessary precautions. Out of these 11 sources, 5 are from Digras city (Patil Nagar, Bajirao Nagar, Vishwashanti Nagar, Deo Nagar and Laxmi Nagar) and other 6 are from different villages (Chincholi, Mandawa, Vitholi, Shivapur, Nimbha and Dehani) of the region.

The $\mathrm{pH}$ and EC were determined immediately after sample collection by instrumental method. Other parameters like total alkalinity (TA), total hardness $(\mathrm{TH})$, fluoride ion concentration, chloride ion concentration, $\mathrm{Ca}^{+2}, \mathrm{Mg}^{+2}$ and 
TDS were analysed in the laboratory by titration method as per standard methods. Karl Pearson's co-efficient of correlation between two variables of all possible pairs was calculated using the following equation-

$$
\mathrm{N} \Sigma(\mathrm{x} . \mathrm{y})-\Sigma \mathrm{x}^{\prime} \Sigma \mathrm{y}^{\prime}
$$

$$
\begin{gathered}
\mathbf{r}=-1 \mathrm{x}^{2} \\
\left\{\mathrm{~N} \Sigma\left[\mathrm{x}^{2}-\left(\mathrm{x}^{\prime}\right)^{2}\right] . \mathrm{N} \Sigma\left[\mathrm{y}^{2}-\left(\mathrm{y}^{\prime}\right)^{2}\right]\right\}^{1 / 2} \\
\text { Where, } \mathrm{N}-\text { Total number of samples. }
\end{gathered}
$$

$\mathrm{x} \& \mathrm{y}$ - Any two parameter values of water quality.

x’ \& y'- Average of x \& y respectively.

The water samples were collected seasonwise (rainy, winter and summer) during the year and their average values were considered for the statistical analysis.

\section{Result and Discussion:-}

As given in the table, the correlation co-efficient values among physic-chemical parameters were found positive as well as negative. The pairs TH-Cl (0.913), TH-Mg(0.915), EC-Cl(0.926), EC-Mg(0.94), EC-TDS(0.934), ClTDS(0.917), $\mathrm{TA}-\mathrm{Mg}(0.934)$ shows significant positive correlation i.e. these parameters affect one another directly. Hence electrical conductance of water depends on $\mathrm{Cl}$ ions, $\mathrm{Mg}$ ions and TDS. Total hardness of water depends on $\mathrm{Ca}$ ions and $\mathrm{Mg}$ ions. Negative correlation exists between $\mathrm{pH}$ and almost all parameters studied, except TA and F ions, which show positive correlation. Similar results were also noted by Krishna et al, Sulochana et.al, Sharma et. $\mathrm{Al}$ and Hussain et. al.

Table :- $\mathrm{r}$ - values for bore well water quality parameters.

\begin{tabular}{|c|c|c|c|c|c|c|c|c|c|}
\hline parameters & $\mathrm{pH}$ & $\mathrm{EC}$ & $\mathrm{TA}$ & $\mathrm{TH}$ & $\mathrm{F}^{-}$ & $\mathrm{Cl}^{-}$ & $\mathrm{Ca}^{+2}$ & $\mathrm{Mg}^{+2}$ & $\mathrm{TDS}$ \\
\hline $\mathrm{pH}$ & 1 & -0.321 & 0.258 & -0.362 & 0.186 & -0.298 & -0.287 & -0.283 & -0.371 \\
$\mathrm{EC}$ & & 1 & 0.112 & 0.681 & -0.245 & 0.926 & 0.684 & 0.94 & 0.934 \\
$\mathrm{TA}$ & & & 1 & 0.068 & 0.213 & 0.235 & -0.317 & 0.934 & 0.047 \\
$\mathrm{TH}$ & & & & 1 & -0.301 & 0.913 & 0.625 & 0.915 & 0.479 \\
$\mathrm{~F}$ & & & & & 1 & 0.264 & 0.162 & -0.204 & -0.314 \\
$\mathrm{Cl}^{-}$ & & & & & & 1 & 0.724 & 0.772 & 0.917 \\
$\mathrm{Ca}^{+2}$ & & & & & & & 1 & 0.647 & 0.658 \\
$\mathrm{Mg}^{+2}$ & & & & & & & & 1 & 0.682 \\
$\mathrm{TDS}$ & & & & & & & & & 1 \\
\hline
\end{tabular}

\section{References:-}

1. J.S.R.Krishna, K.R.Rambabu and C.Rambabu; Indian Journal of Environment Prot. 16,110 (1990).

2. N.Sulochana, K.Selvaraniand B.I.Stephen; Indian Journal of Environment Prot.17, 421 (1997).

3. J.Hussain, K.C.Sharma, I.Hussain, K.G.Ojha and V.K.Vadiya; Asian Journal of Chemistry, 13, 509 (2001).

4. APHA, AWWA-WPCF, Standard method for the Estimation of Water and Waste Water, $15^{\text {th }}$ edition.

5. Laboratory Manual on Water Analysis; NEERI, Nagpur.

6. A Statistical Evaluation of Ground Water Chemistry from the West Coast of Tamil Nadu, India, Asa Rani, I.Bahu, D.S.Suresh.(IJMS, vol.37(2), June 2008.). 